\title{
The antioxidant potential of pyruvate in the amitochondriate diplomonads Giardia intestinalis and Hexamita inflata
}

\author{
Giancarlo A. Biagini, ${ }^{1} \dagger$ Jeong H. Park, ${ }^{1}$ David Lloyd ${ }^{2}$ \\ and Michael R. Edwards ${ }^{1}$
}

Author for correspondence: Giancarlo A. Biagini. Tel: +44 151 7053151. Fax: +44 1517089007. e-mail: Giancarlobiagini@hotmail.com

1 School of Biochemistry and Molecular Genetics, University of New South Wales, Sydney 2052, Australia

2 School of Biosciences, University of Wales Cardiff, Cardiff CF1 3TL, UK
Giardia intestinalis and Hexamita inflata are microaerophilic protozoa which rely on fermentative metabolism for energy generation. These organisms have developed a number of antioxidant defence strategies to cope with elevated $\mathrm{O}_{2}$ tensions which are inimical to survival. In this study, the ability of pyruvate, a central component of their energy metabolism, to act as a physiological antioxidant was investigated. The intracellular pools of 2-oxo acids in $G$. intestinalis were determined by HPLC. With the aid of a dichlorodihydrofluorescein diacetate-based assay, intracellular reactive oxygen species generation by $\boldsymbol{G}$. intestinalis and $\boldsymbol{H}$. inflata suspensions was monitored on-line. Addition of physiologically relevant concentrations of pyruvate to $G$. intestinalis and $\boldsymbol{H}$. inflata cell suspensions was shown to attenuate the rate of $\mathrm{H}_{2} \mathrm{O}_{2}$ - and menadione-induced generation of reactive oxygen species. In addition, pyruvate was also shown to decrease the generation of low-level chemiluminescence arising from the oxygenation of anaerobic suspensions of $H$. inflata. In contrast, addition of pyruvate to suspensions of respiring Saccharomyces cerevisiae was shown to increase the generation of reactive oxygen species. These data suggest that (i) in $G$. intestinalis and $H$. inflata, pyruvate exerts antioxidant activity at physiological levels, and (ii) it is the absence of a respiratory chain in the diplomonads which facilitates the observed antioxidant activity.

Keywords: parasite, oxidative stress, reactive oxygen species, yeast, dichlorodihydrofluorescein diacetate

\section{INTRODUCTION}

The diplomonads Giardia intestinalis and Hexamita inflata are flagellated protozoa which inhabit $\mathrm{O}_{2}$-limited environments. G. intestinalis is a parasite which colonizes the mucosa of the gastrointestinal tract, causing one of the most common water-borne diseases in humans - giardiasis (Adam, 1991). H. inflata is freeliving and can be found in the anoxic regions of marine and freshwater environments (Dando et al., 1993; Fenchel et al., 1995). In addition, parasitic species of Hexamita (which may have free-living stages) have been

\footnotetext{
†Present address: Liverpool School of Tropical Medicine, Penbroke Place, Liverpool L3 5QA, UK.

Abbreviation: SOD, superoxide dismutase.
}

observed in a variety of vertebrate and invertebrate animals (e.g. Kulda \& Nohynková, 1978; Buchmann et al., 1995). The energy demand in these organisms is met by carbohydrate and amino acid fermentation (Brown $e t$ al., 1998; Biagini et al., 1998). The principal products of glucose metabolism include ethanol, alanine, acetate (also lactate for $H$. inflata) and $\mathrm{CO}_{2}$ (Brown et al., 1998; Biagini et al., 1998). Pyruvate is central to this metabolism, and the relative rates of generation of the end-products are influenced by the ambient values for $\mathrm{O}_{2}$ tension (Biagini et al., 1998; Paget et al., 1993a). Both of these organisms lack mitochondria or detectable cytochromes (Brugerolle, 1974; Paget et al., 1993b; Biagini et al., 1997) (and hence oxidative phosphorylation), but do, however, have high affinities for $\mathrm{O}_{2}$, comparable to those of aerobic protozoa (Paget et al., 1993b; Biagini et al., 1997). The consumption of $\mathrm{O}_{2}$ has 
been shown to rise linearly with the surrounding $\mathrm{O}_{2}$ tension, up to a threshold level $\left(30-100 \mu \mathrm{M} \mathrm{O}{ }_{2}\right.$, depending on the species), above which consumption is arrested due to the formation of reactive oxygen species (Paget et al., 1993b; Biagini et al., 1997; Lloyd et al., 2000). The oxygen consumption has been attributed to the activity of $\operatorname{NAD}(\mathrm{P}) \mathrm{H}$ oxidase, and it has been postulated that the subsequent change in the redox state of the $\mathrm{NAD}(\mathrm{P}) \mathrm{H}$ pools affects the relative rates of production of end-products (Brown et al., 1998; Paget et al., 1993a; Biagini et al., 1997).

Much of the energy metabolism in diplomonads more closely resembles that of bacteria than that of eukaryotic cells. Examples include the presence of pyrophosphatedependent glycolytic enzymes (Mertens, 1990; Phillips et al., 1997), the eubacterial-like pyruvate:ferredoxin oxidoreductase (Townson et al., 1996), and the presence of the arginine dihydrolase pathway (Schofield et al., 1990; Biagini et al., 1998; Dimopoulos et al., 2000). The antioxidant defence system in diplomonads is also unlike that found in most eukaryotes. Cysteine replaces glutathione as the major intracellular thiol Brown et al., 1993; G. A. Biagini, D. M. Brown \& M. R. Edwards, unpublished observation in $H$. inflata), and catalase and non-specific peroxidase activities are undetectable (Biagini et al., 1997; Brown et al., 1995). An Fe-type superoxide dismutase (SOD) has been described for $H$. inflata (Biagini et al., 1997) and, although SOD activity was initially reported in Giardia (Thompson et al., 1993), in a more recent study SOD activity was undetectable even after induction with 1,10-phenanthroline (Brown et al., 1995). In addition, G. intestinalis contains a thioredoxin-reductase-like disulphide reductase which has the ability to reduce cystine (Brown et al., 1996), whereas $H$. inflata contains an as yet uncharacterized thiol reductase which may be involved in cystine reduction (Biagini et al., 1997).

The ability of pyruvate to react with $\mathrm{H}_{2} \mathrm{O}_{2}$ (and ${ }^{\cdot} \mathrm{O}_{2}^{-}$), forming acetate and $\mathrm{CO}_{2}$ non-enzymically, has long been known (Holleman, 1904). However, whether pyruvate plays a physiological role as an $\mathrm{H}_{2} \mathrm{O}_{2}$ scavenger in cells is not clear. In this study, we report on the ability of pyruvate, a central component of diplomonad metabolism, to act as an intracellular scavenger of reactive oxygen species in both G. intestinalis and H. inflata. The contrasting physiological roles of pyruvate in oxidative and fermentative metabolism are discussed.

\section{METHODS}

Organisms and solutions. The G. intestinalis Portland 1 strain and $H$. inflata were grown as described previously (Knodler $e t$ al., 1994; Biagini et al., 1997). For experimentation, cells were grown to late-exponential phase, harvested by centrifugation at $650 \mathrm{~g}$ for $5 \mathrm{~min}$ and resuspended in PBS buffer $(\mathrm{pH} 7 \cdot 2)$ containing $150 \mathrm{mM} \mathrm{NaCl}, 5 \mathrm{mM} \mathrm{K}_{2} \mathrm{HPO}_{4}$ and $1.8 \mathrm{mM}$ $\mathrm{KH}_{2} \mathrm{PO}_{4}$. Saccharomyces cerevisiae (a laboratory wild-type strain) was grown in YPD medium containing $1 \%(\mathrm{w} / \mathrm{v})$ yeast extract, $2 \%(\mathrm{w} / \mathrm{v})$ bacteriological peptone and $2 \%(\mathrm{w} / \mathrm{v}) \mathrm{D}-$ glucose, in a shaking incubator at $30^{\circ} \mathrm{C}$. For experimentation, cells were grown to mid-exponential phase, harvested by centrifugation at $1000 \mathrm{~g}$ for $5 \mathrm{~min}$ and resuspended in PBS. Pyruvate (the $\mathrm{Na}$ salt), menadione and $\mathrm{H}_{2} \mathrm{O}_{2}$ solutions were prepared freshly on the day of experimentation.

Determination of intracellular 2-oxo acid pools in $\mathbf{G}$. intestinalis. Pre-purification, derivatization and subsequent separation of 2-oxo acids in giardial extracts were based on the methods described by Hayashi et al. (1982) and Liao et al. (1977). Dry polyacrylamide beads (15 g Bio-Gel P-60) were allowed to swell overnight in distilled water $(200 \mathrm{ml})$. The gel suspension was then added to a $98 \%$ hydrazine hydrate solution $(120 \mathrm{ml})$ and mixed for $6 \mathrm{~h}$ at $50{ }^{\circ} \mathrm{C}$. At the end of the reaction period, the gel was washed free of hydrazine with $0.1 \mathrm{M} \mathrm{NaCl}$ and suspended in a storage solution containing $0 \cdot 2 \mathrm{M} \mathrm{NaCl}, 0.02 \mathrm{M} \mathrm{Na}_{2}$ EDTA, 0.1 $\mathrm{M} \mathrm{H}_{3} \mathrm{BO}_{3}, 5 \mathrm{mM} \mathrm{NaOH}$ and $5 \mu \mathrm{M}$ pentachlorophenol at $4{ }^{\circ} \mathrm{C}$. Cell suspensions in PBS were centrifuged at $10000 \mathrm{~g}$ through oil (a mixture of dibutyl phthalate and diiso-octyl phthalate, $4: 1, \mathrm{v} / \mathrm{v} ; 1.03 \mathrm{~g} \mathrm{ml}^{-1}$ ) into $0 \cdot 1 \mathrm{ml} 1 \mathrm{M}$ perchloric acid. The perchloric acid extract was placed on ice for $1 \mathrm{~h}$ and then centrifuged at $10000 \mathrm{~g}$ for $1 \mathrm{~min}$. To $0 \cdot 1 \mathrm{ml}$ of the supernatant from the perchloric acid extract, $0.2 \mathrm{ml}$ of an internal standard solution of 2-oxo-octanoate $(80 \mu \mathrm{M})$ together with $1 \mathrm{ml} 0 \cdot 1 \mathrm{M}$ acetic acid and $3 \mathrm{ml} 0 \cdot 1 \mathrm{M}$ $\mathrm{NaCl}$ were added. The mixture was then loaded onto a glass column containing the $0.3 \mathrm{ml}$ of hydrazide gel. After elution was complete, the gel was washed five times with $0 \cdot 1 \mathrm{M} \mathrm{NaCl}$ and then transferred to a test tube; $O$-phenylenediamine solution $(2 \mathrm{ml})$ was added to the gel and this was then incubated at $80^{\circ} \mathrm{C}$ for $2 \mathrm{~h}$, after which $0.5 \mathrm{~g} \mathrm{Na}_{2} \mathrm{SO}_{4}$ was added. The derivatives of the 2-oxo acids were extracted with ethyl acetate, evaporated to dryness under a stream of $\mathrm{N}_{2}$, and the residue was dissolved in methanol. HPLC was carried out with a $250 \times 4 \mathrm{~mm}$ Li-Chrosorb RP-8 (Capital HPLC) $(5 \mu \mathrm{m}$ particle size) column. The mobile phase consisted of a $6: 4$ methanol: water mix operating at a flow rate of $1 \mathrm{ml} \mathrm{min}^{-1}$ at $35^{\circ} \mathrm{C}$. The overall recovery of 2 -oxo acids measured using radiolabelled pyruvate and 2-oxoglutarate was $72 \pm 7 \%$.

Determination of intracellular amino acid pools in $\mathbf{G}$. intestinalis. Intracellular amino acid analysis was performed as described previously (Knodler et al., 1994), with 3aminopropionate as the internal standard, on a Beckman 6300 amino acid analyser.

Flow cytometry. Cellular fluorescence (green emission, 530$540 \mathrm{~nm}$ ) was monitored by flow cytometry using a MoFlo cytometer (Cytomation PTY) with excitation at $488 \mathrm{~nm}$ from a water-cooled $200 \mathrm{~mW}$ argon-ion laser. In addition, forward light scatter and right-angle side scatter were measured and used for gating data collection. Typically, signals from $\geqslant 50000$ cells were acquired and analysed using Cyclops software (Cytomation PTY) for each sample. The flowcytometric histogram shown is representative of at least three independent experiments performed with both $G$. intestinalis and H. inflata.

Monitoring of intracellular reactive oxygen species production. Dichlorodihydrofluorescein diacetate $\left(\mathrm{H}_{2} \mathrm{DCFDA}\right.$; Molecular Probes) was used to detect the intracellular generation of reactive oxygen intermediates (predominantly $\mathrm{H}_{2} \mathrm{O}_{2}$ ). $\mathrm{H}_{2}$ DCFDA was added (final concentration $2 \mu \mathrm{M}$ ) to suspensions of $G$. intestinalis and H. inflata in PBS (approx. $5 \times 10^{6}$ cells $\mathrm{ml}^{-1}$ ) and fluorescence was measured by flow cytometry or on-line using a Perkin Elmer LS 50B luminescence spectrophotometer (excitation $504 \mathrm{~nm}$, emission $527 \mathrm{~nm}$ ). $\mathrm{H}_{2}$ DCFDA is non-fluorescent and is able to permeate biological membranes. Once in the cytosol, esterase activity 
renders the indicator non-permeant by forming the fluorescent product dichlorofluorescein, and the fluorescence intensity of the dye is proportional to the rate of oxidation by reactive oxygen species (predominantly $\mathrm{H}_{2} \mathrm{O}_{2}$ ). The fluorescence signals detected from $H$. inflata $\mathrm{H}_{2}$ DCFDA-loaded cells were larger than those from $G$. intestinalis and $S$. cerevisiae cells. These differences are believed to reflect dye-loading efficiencies and do not compromise the assays. The fluorescence traces shown are representative of at least three independent experiments performed with both $G$. intestinalis and $H$. inflata.

Measurement of photo-emissive $\mathrm{O}_{2}$-reduction products in $\boldsymbol{H}$.

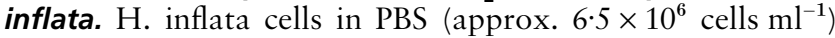
were exposed to low levels of dissolved $\mathrm{O}_{2}$ in a continuously stirred reactor (200 r.p.m.) fitted with an observation window for photon counting (Lloyd et al., 1979, 1985). The reactor was open for gas exchange from a mobile gas phase, the composition of which was controlled using a gas mixer; dissolved $\mathrm{O}_{2}$ was monitored using a Radiometer electrode. A Peltier-cooled, red-sensitive, photon-counting photo-multiplier device (EMI 9817) provided continuous monitoring of weak chemiluminescence emission $(>900 \mathrm{~nm}$ ) without spectral discrimination. The $\mathrm{O}_{2}$ concentration of air-saturated water at $25^{\circ} \mathrm{C}$ was taken to be $253 \mu \mathrm{M} \mathrm{O}_{2}$ (Wilhelm et al., 1977). Data are representative of three experiments.

\section{RESULTS}

Initially, the study was concerned with measuring the physiological level of pyruvate and other 2-oxo acids in G. intestinalis. As described in Methods, 2-oxo acids were pre-purified from the cell extracts using hydrazide gel, and were derivatized with $o$-phenylenediamine, producing the 2-quinoxalinol derivatives. The prepurification of 2-oxo acids was essential, since without this step, no discrete separation was observed. The intracellular 2-oxo acid pool concentrations in $G$. intestinalis together with those of their amino acid counterparts (for comparison) are given in Table 1 . The number of intracellular 2-oxo acids was smaller, and their concentrations lower, than those of their amino acid counterparts, only seven 2-oxo acids versus 25 amino acids being detected (not all shown). The major 2 -oxo acid detected was pyruvate $(0.5 \mathrm{mM})$, which is consistent with its amino form, alanine, being present at the highest intracellular concentration. As H. inflata has a similar intracellular concentration of amino acids to that of G. intestinalis (Biagini et al., 2000), it was therefore assumed that their pyruvate levels would also be comparable. Experiments were then conducted to test whether pyruvate, added at concentrations close to physiological levels, would confer protection against reactive oxygen species.

We have previously observed that incubation of diplomonads in air-saturated solutions results in the generation of reactive oxygen species (e.g. $\mathrm{H}_{2} \mathrm{O}_{2}$ ) (Biagini et al., 1997; Lloyd et al., 2000). An $\mathrm{H}_{2}$ DCFDA-based assay was designed (see Methods) to monitor the intracellular generation of reactive oxygen species on-line.

Flow cytometry was used to confirm that fluorescence of $\mathrm{H}_{2}$ DCFDA-loaded $G$. intestinalis and $H$. inflata cells was arising intracellularly. Analysis of unstained $H$. inflata cells in PBS revealed a small degree of autofluorescence, whereas $\mathrm{H}_{2}$ DCFDA-loaded cells $(15 \mathrm{~min}$ incubation) were observed to have a significantly increased intracellular fluorescence intensity (Fig. 1). Addition of $\mathrm{H}_{2} \mathrm{O}_{2}(200 \mu \mathrm{M})$ to $\mathrm{H}_{2}$ DCFDA-loaded cells further increased intracellular fluorescence, indicating free diffusion of $\mathrm{H}_{2} \mathrm{O}_{2}$ into the cell cytosol. Prior incubation of $\mathrm{H}_{2}$ DCFDA-loaded cells with pyruvate $(1 \mathrm{mM}, 5 \mathrm{~min})$ attenuated the $\mathrm{H}_{2} \mathrm{O}_{2}$-induced fluorescence (Fig. 1). Similar results were also observed with G. intestinalis trophozoites (not shown).

The scavenging activity of pyruvate was monitored in real time with a luminescence spectrophotometer. Fluorescence from $\mathrm{H}_{2}$ DCFDA-loaded $H$. inflata cells was monitored after the addition of $200 \mu \mathrm{M} \mathrm{H}_{2} \mathrm{O}_{2}$ (Fig. 2). Pyruvate was shown to reduce the rate of reactive oxygen species generation (as indicated by the rate of increase in fluorescence intensity), the degree of attenuation being proportional to the pyruvate concentration (Fig. 2). Heat-fixed (60 $\left.{ }^{\circ} \mathrm{C}, 15 \mathrm{~min}\right) \mathrm{H}_{2}$ DCFDAloaded cells were used as a negative control. A smaller but significant decrease in the rate of $\mathrm{H}_{2} \mathrm{O}_{2}$-induced reactive oxygen species generation by pyruvate was also observed in $G$. intestinalis (Table 2). Addition of pyruvate metabolism end-products such as ethanol, alanine and acetate (up to $3 \mathrm{mM}$ ) was shown not to decrease the rate of $\mathrm{H}_{2} \mathrm{O}_{2}$-induced reactive oxygen species generation in $H$. inflata or $G$. intestinalis.

Table 1. Intracellular 2-oxo acids and their amino forms in G. intestinalis

Values are means $\pm \mathrm{SD}(n=10)$.

\begin{tabular}{|lllr|}
\hline 2-Oxo acid & Concn $(\mathbf{m M})$ & 2-Amino form & Concn $(\mathbf{m M})$ \\
\hline 2-Oxoglutarate & $0 \cdot 14 \pm 0 \cdot 03$ & Glutamate & $17 \cdot 8 \pm 1 \cdot 2$ \\
Glyoxylate & $0 \cdot 31 \pm 0 \cdot 05$ & Glycine & $7 \cdot 9 \pm 0 \cdot 8$ \\
Pyruvate & $0 \cdot 49 \pm 0 \cdot 08$ & Alanine & $54 \cdot 3 \pm 1 \cdot 9$ \\
2-Oxo-n-butyrate & $0 \cdot 31 \pm 0 \cdot 04$ & 2-Amino-n-butyrate & $0 \cdot 5 \pm 0 \cdot 2$ \\
2-Oxoisovalerate & $0 \cdot 08 \pm 0 \cdot 02$ & Valine & $5 \cdot 3 \pm 0 \cdot 8$ \\
2-Oxoisocaproate & $0 \cdot 28 \pm 0 \cdot 05$ & Leucine & $4 \cdot 2 \pm 0 \cdot 5$ \\
2-Oxocaproate & $0 \cdot 16 \pm 0 \cdot 03$ & Isoleucine & $2 \cdot 2 \pm 0 \cdot 2$ \\
\hline
\end{tabular}




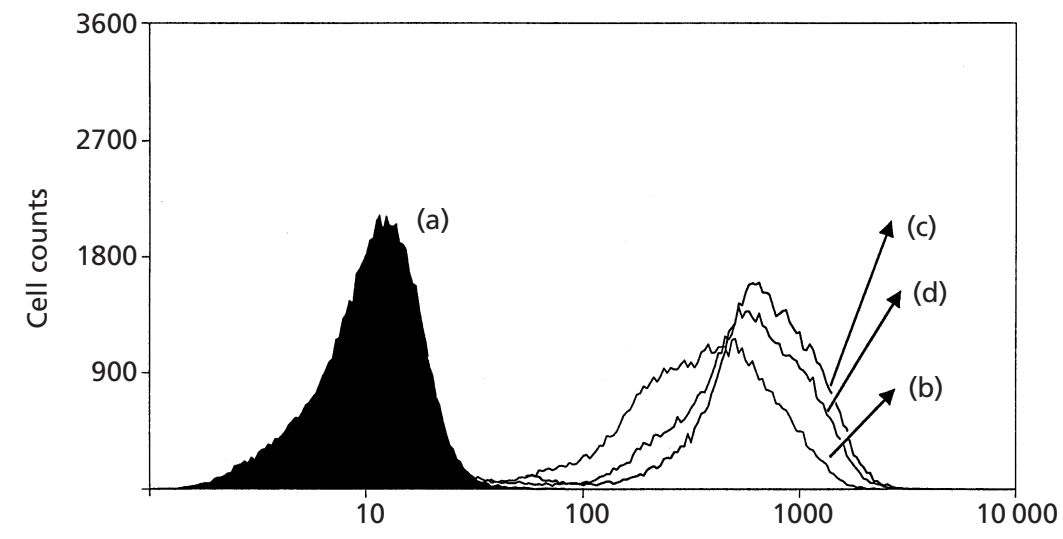

Fluorescence intensity (arbitrary units)
Fig. 1. Flow cytometric histograms of intracellular fluorescence intensity $(488 \mathrm{~nm}$ excitation, $530-540 \mathrm{~nm}$ emission) in $H$. inflata trophozoites. The various cell populations reflect different treatments: (a) intrinsic autofluorescence, (b) fluorescence arising from $\mathrm{H}_{2}$ DCFDA-loaded cells, (c) $\mathrm{H}_{2}$ DCFDA-loaded cells in the presence of $200 \mu \mathrm{M} \mathrm{H}_{2} \mathrm{O}_{2}$ and (d) $\mathrm{H}_{2}$ DCFDA-loaded cells, previously incubated with pyruvate $(1 \mathrm{mM})$, in the presence of $200 \mu \mathrm{M} \mathrm{H}_{2} \mathrm{O}_{2}$.

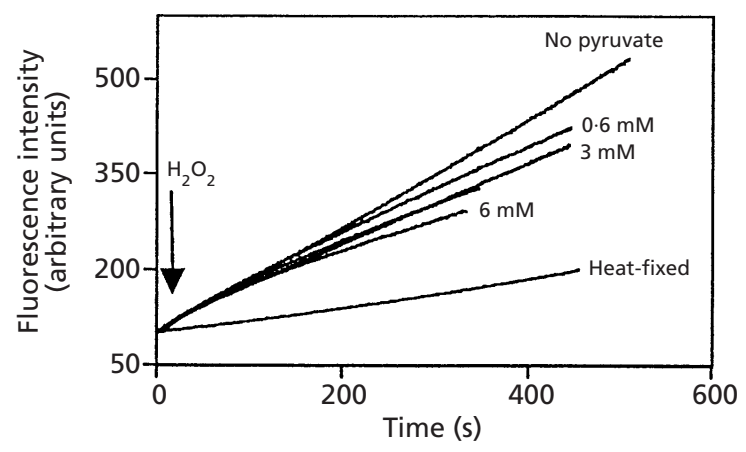

Fig. 2. Fluorimetric traces of $H$. inflata $\mathrm{H}_{2}$ DCFDA-loaded cells. Increases in fluorescence are representative of increases in the rate of oxidative species generated (see Methods). Fluorescence was monitored from suspensions of live and heat-fixed cells $\left(60^{\circ} \mathrm{C}, 15 \mathrm{~min}\right)$ after the addition of $\mathrm{H}_{2} \mathrm{O}_{2}(200 \mu \mathrm{M})$ in the absence and presence of various concentrations of pyruvate.

Menadione was also used to induce the generation of intracellular reactive oxygen species (predominantly $\left.\cdot \mathrm{O}_{2}^{-}\right)$. Fluorescence arising from $\mathrm{H}_{2}$ DCFDA-loaded $G$.

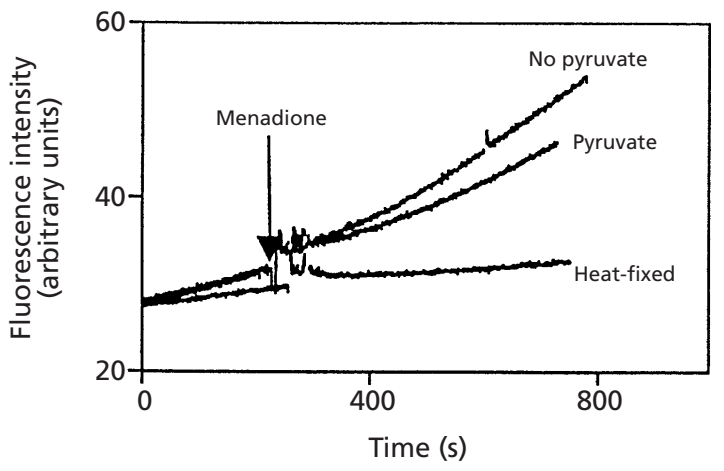

Fig. 3. Fluorimetric traces of $G$. intestinalis $\mathrm{H}_{2} \mathrm{DCFDA}$-loaded cells. Fluorescence intensity was monitored from suspensions of live and heat-fixed cells $\left(60^{\circ} \mathrm{C}, 15 \mathrm{~min}\right)$ after the addition of menadione $(300 \mu \mathrm{M})$ in the absence and presence of pyruvate (1 mM).

intestinalis cells was shown to increase upon the addition of $300 \mu \mathrm{M}$ menadione (Fig. 3). The increase in the rate of fluorescence intensity (and thus the increase in the rate

Table 2. Effect of pyruvate on $\mathrm{H}_{2} \mathrm{O}_{2}$ - and menadione $\left({ }^{\circ} \mathrm{O}_{2}^{-}\right)$-induced generation of oxygen species in $\mathrm{G}$. intestinalis and $\mathrm{H}$. inflata, as measured by intracellular $\mathrm{H}_{2}$ DCFDA fluorescence

\begin{tabular}{|lccrr|}
\hline Organism & $\begin{array}{c}\text { Major reactive } \\
\text { oxygen species }\end{array}$ & $\begin{array}{c}\text { Pyruvate concn } \\
(\mathbf{m M})\end{array}$ & Inhibition $(\%) *$ & $\boldsymbol{P}+$ \\
\hline Giardia & $\cdot \mathrm{O}_{2}^{-}$ & 1 & $27 \cdot 4 \pm 0 \cdot 8$ & $<0 \cdot 001$ \\
Giardia & $\mathrm{H}_{2} \mathrm{O}_{2}$ & $0 \cdot 6$ & $2 \cdot 3 \pm 0 \cdot 9$ & $0 \cdot 025$ \\
Giardia & $\mathrm{H}_{2} \mathrm{O}_{2}$ & 3 & $5 \cdot 9 \pm 0 \cdot 6$ & $<0 \cdot 001$ \\
Giardia & $\mathrm{H}_{2} \mathrm{O}_{2}$ & 6 & $8 \cdot 7 \pm 1 \cdot 5$ & $0 \cdot 001$ \\
Hexamita & $\cdot \mathrm{O}_{2}^{-}$ & 1 & $6 \cdot 7 \pm 1 \cdot 2$ & $0 \cdot 001$ \\
Hexamita & $\mathrm{H}_{2} \mathrm{O}_{2}$ & $0 \cdot 6$ & $13 \cdot 3 \pm 0 \cdot 5$ & $<0 \cdot 001$ \\
Hexamita & $\mathrm{H}_{2} \mathrm{O}_{2}$ & 3 & $25 \cdot 2 \pm 0 \cdot 4$ & $<0 \cdot 001$ \\
Hexamita & $\mathrm{H}_{2} \mathrm{O}_{2}$ & 6 & $40 \cdot 8 \pm 0 \cdot 3$ & $<0 \cdot 001$ \\
\hline
\end{tabular}

*Values are means \pm SD $(n=3)$ of independent experiments.

$\dagger P$ values (two-tailed $t$-test) for differences between fluorescence values in the presence and absence of pyruvate after 6 min incubation with either menadione $(300 \mu \mathrm{M})$ or $\mathrm{H}_{2} \mathrm{O}_{2}(200 \mu \mathrm{M})$. 


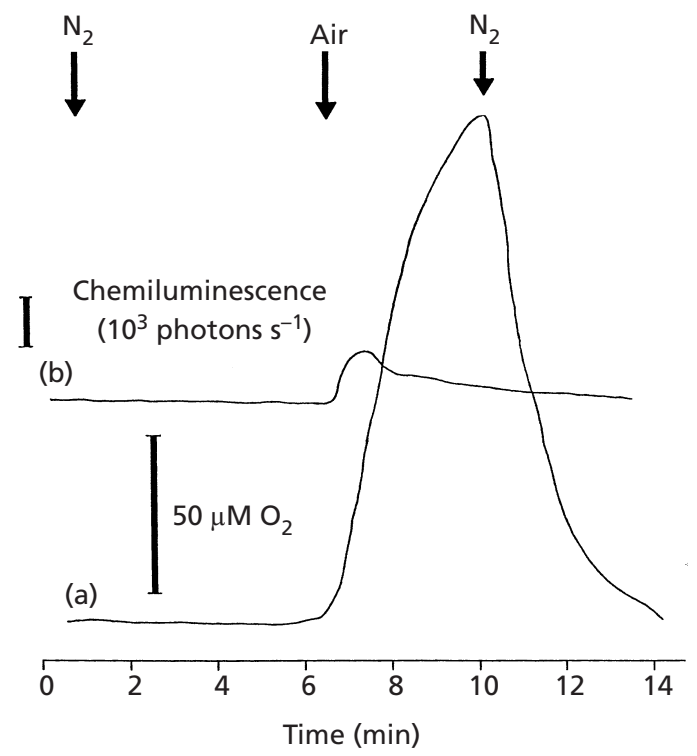

Fig. 4. Chemiluminescence of a whole-cell suspension of $H$. inflata. Low-level chemiluminescence was monitored in a continuously stirred reactor, open for gas exchange. Traces indicate the response of an anaerobic suspension of $\mathrm{H}$. inflata in PBS to oxygenation. (a) $\left[\mathrm{O}_{2}\right]$, (b) chemiluminescence.

of reactive oxygen species generation) with menadione was shown to be reduced by the addition of $1 \mathrm{mM}$ pyruvate (Fig. 3). Heat-fixed $\left(60^{\circ} \mathrm{C}, 15 \mathrm{~min}\right) \mathrm{H}_{2}$ DCFDAloaded cells were used as a negative control. Duplication of the experiment using $H$. inflata cells also resulted in pyruvate $(1 \mathrm{mM})$ reducing the rate of menadioneinduced reactive oxygen species generation, but to a lesser extent than that shown for $G$. intestinalis (Table 2).

Low-level chemiluminescence arises from cells predominantly as a result of singlet $\mathrm{O}_{2}$ generation (e.g. during lipid peroxidation). As such, measurement of low-level chemiluminescence is a useful assay for the monitoring of oxidative stress. Low-level chemiluminescence was observed upon oxygenation of an anaerobic suspension of $H$. inflata cells (Fig. 4). Prior anaerobic incubation of trophozoites with pyruvate (1 $\mathrm{mM})$ dramatically lowered the burst of chemiluminescence occurring upon oxygenation of the suspending solution (Fig. 5).

One of the hypotheses leading to this study was that the observed reactive oxygen species scavenging activity of pyruvate favoured anaerobic energy metabolism over oxidative metabolism. To test this hypothesis, $S$. cerevisiae cells (which had been grown aerobically) in PBS were loaded with $\mathrm{H}_{2}$ DCFDA and the subsequent fluorescence was monitored continuously with the luminescence spectrophotometer. The fluorescence arising from the $\mathrm{H}_{2}$ DCFDA-loaded yeast cells was shown to increase proportionally with pyruvate concentration (Fig. 6a). In addition, the rate of increase in fluorescence intensity in $\mathrm{H}_{2}$ DCFDA-loaded yeast cells, oxidatively

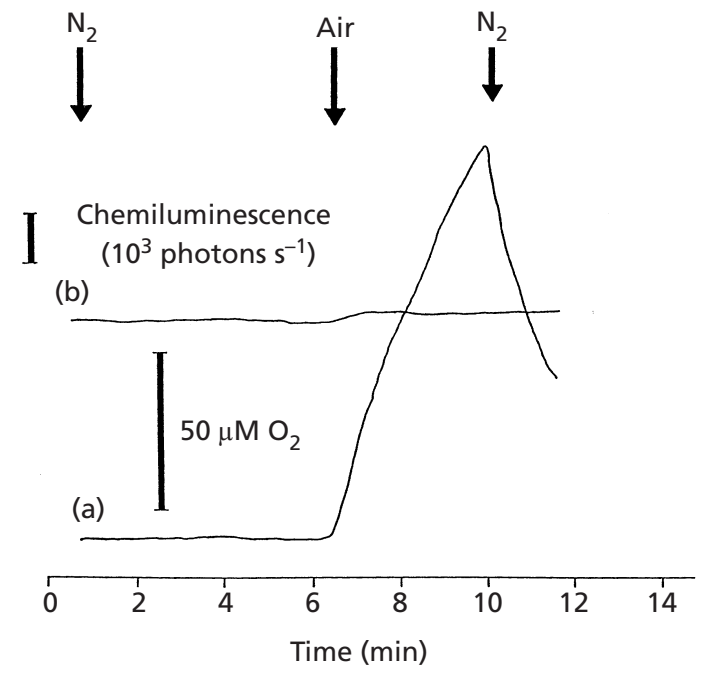

Fig. 5. Chemiluminescence of a whole-cell suspension of $H$. inflata. Traces indicate the response of an anaerobic suspension of $H$. inflata in PBS to oxygenation in the presence of pyruvate (1 mM). (a) $\left[\mathrm{O}_{2}\right]$, (b) chemiluminescence.

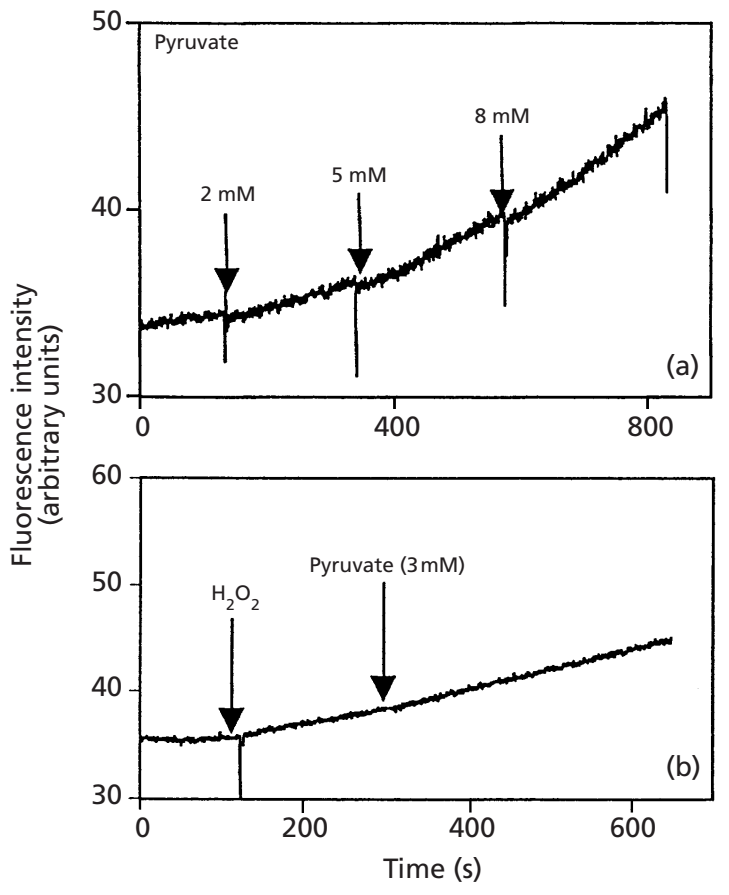

Fig. 6. Fluorimetric traces of $S$. cerevisiae $\mathrm{H}_{2}$ DCFDA-loaded cells. (a) Fluorescence intensity was monitored from a cell suspension of $S$. cerevisiae in PBS during the addition of various concentrations of pyruvate. (b) Fluorescence intensity was monitored from a cell suspension of $S$. cerevisiae in PBS after the addition of $\mathrm{H}_{2} \mathrm{O}_{2}(200 \mu \mathrm{M})$ and pyruvate $(3 \mathrm{mM})$.

stressed by the addition of $\mathrm{H}_{2} \mathrm{O}_{2}(200 \mu \mathrm{M})$, was not attenuated by the addition of up to $3 \mathrm{mM}$ pyruvate (Fig. $6 \mathrm{~b})$. These data indicate that, under our in vitro conditions, pyruvate does not have a net antioxidant 
activity in aerobically grown yeast, but rather is acting as a generator of reactive oxygen species.

\section{DISCUSSION}

In this study we have measured the intracellular levels of 2 -oxo acids, including pyruvate, in G. intestinalis. The ability of pyruvate, added at concentrations close to physiological levels, to act as an oxidative species 'scavenger' was then investigated in both G. intestinalis and $H$. inflata. The effect of pyruvate on the generation of reactive oxygen species in the fermentative diplomonads was then compared with that in respiring $S$. cerevisiae.

As shown in Table 1, the 2-oxo acid pools in $G$. intestinalis were shown to be smaller in number and at lower concentrations than their amino forms. Values for the intracellular amino acids were very similar to those reported previously (Knodler et al., 1994). The ratio of the pyruvate pool to the alanine pool was almost identical to that of the 2-oxoglutarate pool to the glutamate pool, suggesting that the reaction catalysed by alanine aminotransferase is approximately at equilibrium in this parasite. In addition to alanine, the other neutral amino acids glycine, valine, leucine and isoleucine that contribute significantly to the total amino acid pool were represented by the respective oxo-acids glyoxylate, 2-oxoisovalerate, 2-oxoisocaproate and 2oxocaproate in the oxo acid pool. However, no oxoaloacetate pool was detected, although G. intestinalis contains aspartate aminotransferase activity (Edwards et al., 1994). The lack of detectable oxaloacetate may be due to its instability; alternatively, it may simply be present at undetectable levels because of the high activity of malate dehydrogenase, favouring oxaloacetate reduction. In addition, the 2-oxo acid forms of the aromatic acids phenylalanine and tyrosine were undetectable. This was also unexpected in view of the aromatic aminotransferase activities that have been previously observed in G. intestinalis (Edwards et al., 1994).

Biological membranes are readily permeable to pyruvate and it can therefore be assumed that the extracellular addition of pyruvate would raise, at least transiently, the levels of intracellular pyruvate. With the aid of the $\mathrm{H}_{2}$ DCFDA-based assays, intracellular generation of reactive oxygen species by $G$. intestinalis and $H$. inflata was monitored in real time. As expected, the addition of $\mathrm{H}_{2} \mathrm{O}_{2}$ (which is uncharged and therefore freely penetrates the plasma membrane) was shown to increase the rate of intracellular generation of reactive oxygen species (as indicated by the increase in fluorescence intensity; Fig. 2, Table 2). Similarly, the addition of the synthetic quinone menadione increased the rate of intracellular generation of reactive oxygen species (Fig. 3 , Table 2). Both $\mathrm{H}_{2} \mathrm{O}_{2}$ - and menadione-induced generation of reactive oxygen species in the diplomonads were reduced by the addition of pyruvate. Pyruvate was shown to be more effective at reducing menadioneinduced generation of reactive oxygen species (pre- dominantly ${ }^{\circ} \mathrm{O}_{2}^{-}$) in G. intestinalis than in $H$. inflata (Table 2). Conversely, pyruvate was shown to be more effective at reducing $\mathrm{H}_{2} \mathrm{O}_{2}$-induced generation of reactive oxygen species in $H$. inflata than in $G$. intestinalis (Table 2). This disparity could be explained by the different antioxidant systems present in these organisms, e.g. H. inflata contains an Fe-type SOD (Biagini et al., 1997), whereas SOD is undetectable in G. intestinalis (Brown et al., 1995).

Pyruvate was also shown to reduce the generation of weak chemiluminescence arising from the oxygenation of the suspending solution (Fig. 4). These data signify that pyruvate, in vivo, may play a significant role as a low-molecular-mass antioxidant in G. intestinalis and $H$. inflata, protecting the cells from both the generation and propagation (as indicated by the reduction of singlet $\mathrm{O}_{2}$ production) of reactive oxygen species. It is also possible that the other 2-oxo acids detected, such as 2oxoglutarate (which has known $\mathrm{H}_{2} \mathrm{O}_{2}$-scavenging activity; Halliwell \& Gutteridge, 1999), may also act as physiological antioxidants.

In contrast to the effect of pyruvate in diplomonads, the addition of pyruvate to yeast had no observable antioxidant effect, but rather caused an increase in the rate of generation of reactive oxygen species (Fig. 6). The oxidative respiratory chain is a major source of $\mathrm{H}_{2} \mathrm{O}_{2}$ and other oxygen radicals (e.g. ' $\mathrm{O}_{2}^{-}$) due to 'leaky' redox reactions (e.g. Halliwell \& Gutteridge, 1999). It is therefore probable that pyruvate in respiring yeast cells acts to increase the generation of reactive oxygen species by increasing the flux of electrons down the respiratory chain.

In a recent elegant study performed by Brand \& Hermfisse (1997), the phenomenon of aerobic glycolysis was investigated in mitogen-activated rat thymocytes. Resting thymocytes were observed to meet their ATP demand largely by oxidative glucose catabolism, whereas the energy demand of proliferating thymocytes was satisfied by glycolysis. Decreased reactive oxygen species generation, due to the shut-down of respiration as well as an observed increase in the pyruvate pool during glycolytic metabolism, were suggested as metabolic strategies employed by the cell to minimize oxidative stress during cell division. It appears, therefore, that pyruvate can act to induce or to scavenge reactive oxygen species, depending on the metabolic mode (e.g. oxidative or glycolytic) of the cell. In diplomonads, where components of the respiratory chain are undetectable (e.g. cytochromes), the fermentative energy metabolism results in pyruvate acting as an efficient scavenger of reactive oxygen species. Whether these two diplomonads have the ability to regulate pyruvate levels in response to oxidative stress remains to be determined. It is conceivable, however, that previously described changes in metabolic end-product formation (Paget et al., 1993a; Biagini et al., 1998) may indirectly promote a rise in the intracellular pyruvate availability in response to moderate increases in $\mathrm{O}_{2}$ tension. 


\section{ACKNOWLEDGEMENTS}

This work was supported by the Australian Research Council and by The Royal Society (D.L.).

\section{REFERENCES}

Adam, R. D. (1991). The biology of Giardia spp. Microbiol Rev 55, 706-732.

Biagini, G. A., Suller, M. T. E., Finlay, B. J. \& Lloyd, D. (1997). Oxygen uptake and antioxidant responses of the free-living diplomonad Hexamita sp. J Eukaryot Microbiol 44, 447-453.

Biagini, G. A., Mclntyre, P. S., Finlay, B. J. \& Lloyd, D. (1998). Carbohydrate and aminoacid fermentation in the free-living primitive protozoon Hexamita sp. Appl Environ Microbiol 64, 203-207.

Biagini, G. A., Kirk, K., Schofield, P. J. \& Edwards, M. R. (2000). Role of $\mathrm{K}^{+}$and amino acids in osmoregulation by the free-living microaerophilic protozoon Hexamita inflata. Microbiology 146, 427-433.

Brand, K. A. \& Hermfisse, U. (1997). Aerobic glycolysis by proliferating cells: a protective strategy against reactive oxygen species. FASEB J 11, 388-395.

Brown, D. M., Upcroft, J. A. \& Upcroft, P. (1993). Cysteine is the major low molecular weight thiol in Giardia duodenalis. Mol Biochem Parasitol 61, 155-158.

Brown, D. M., Upcroft, J. A. \& Upcroft, P. (1995). Free-radical detoxification in Giardia duodenalis. Mol Biochem Parasitol 72, 47-56.

Brown, D. M., Upcroft, J. A. \& Upcroft, P. (1996). A thioredoxin reductase-class of disulphide reductase in the protozoan parasite Giardia duodenalis. Mol Biochem Parasitol 83, 211-220.

Brown, D. M., Upcroft, J. A., Edwards, M. R. \& Upcroft, P. (1998). Anaerobic bacterial metabolism in the ancient eukaryote Giardia duodenalis. Int J Parasitol 28, 149-164.

Brugerolle, G. (1974). Contribution a l'etude cytologique et phyletique des diplozaires (zoomastigophorea, diplozoa, Dangeard 1910). Protistologica 1, 83-90.

Buchmann, K., Uldal, A. \& Lyholt, H. C. K. (1995). Parasite infections in Danish trout farms. Acta Vet Scand 36, 283-298.

Dando, P. R., Fenchel, T., Jensen, P., O'Hara, S. C. M., Niven, S. J. \& Schuster, U. (1993). Ecology of gassy, organic-rich sediment in a shallow subtidal area on the kattegat coast of Denmark. Mar Ecol Prog Ser 100, 265-271.

Dimopoulos, M., Bagnara, A. S. \& Edwards, M. R. (2000). Characterisation and sequence analysis of a carbamate kinase gene from the diplomonad Hexamita inflata. J Eukaryot Microbiol 47, 499-503.

Edwards, M. R., Payne, K. D., Wilson, J. R. \& Schofield, P. J. (1994). Giardial aminotransferases. In Giardia from Molecules to Disease, pp. 189-191. Edited by R. C. A. Thompson, J. A. Reynoldson \& A. J. Lymbery. Wallingford: CAB International.

Fenchel, T., Bernard, C., Esteban, G., Finlay, B. J., Hansen, P. J. \& Iversen, N. (1995). Microbial diversity and activity in a Danish fjord with anoxic deep water. Ophelia 43, 45-100.
Halliwell, B. \& Gutteridge, J. M. C. (1999). Free Radicals in Biology and Medicine. Oxford: Oxford University Press.

Hayashi, T., Tsuchiya, H., Todoriki, H. \& Naruse, H. (1982). Highperformance liquid chromatography determination of alpha-keto acids in human urine and plasma. Anal Biochem 122, 173-179.

Holleman, A. F. (1904). Lehrbuch der organischen Chemie. Leipzig: Veit

Knodler, L. A., Edwards, M. R. \& Schofield, P. J. (1994). The intracellular amino acid pools of Giardia intestinalis, Trichomonas vaginalis and Crithidia luciliae. Exp Parasitol 79, 117-125.

Kulda, J. \& Nohynková, E. (1978). Flagellates of the human intestine and of the intestines of other species. In Parasitic Protozoa, pp. 2-127. Edited by J. P. Kreier. New York: Academic Press.

Liao, J. C., Hoffman, N. E., Barboriak, J. J. \& Roth, D. A. (1977). High-performance liquid chromatography of pyruvic and alphaketoglutaric acids and its application to urine samples. Clin Chem 23, 802-805.

Lloyd, D., Boveris, A., Reiter, R., Filipkowski, M. \& Chance, B. (1979). Chemiluminescence of Acanthamoeba castellanii. Biochem J 184, 149-156.

Lloyd, D., James, C. J. \& Hastings, J. W. (1985). Oxygen affinities of the bioluminescence systems of various species of luminous bacteria. J Gen Microbiol 131, 2137-2140.

Lloyd, D., Harris, J. C., Maroulis, S., Biagini, G. A., Wadley, R. B., Turner, M. P. \& Edwards, M. R. (2000). The microaerophilic flagellate Giardia intestinalis: oxygen and its reaction products collapse membrane potential and cause cytotoxicity. Microbiology 146, 3109-3118.

Mertens, E. (1990). Occurrence of pyrophosphate:fructose 6phosphate 1-phosphotransferase in Giardia lamblia trophozoites. Mol Biochem Parasitol 40, 147-149.

Paget, T. A., Kelly, M. L., Jarroll, E. L., Lindmark, D. G. \& Lloyd, D. (1993a). The effects of oxygen on fermentation in Giardia lamblia. Mol Biochem Parasitol 57, 65-72.

Paget, T. A., Manning, P. \& Jarroll, E. L. (1993b). Oxygen uptake in cysts and trophozoites of Giardia lamblia. J Euk Microbiol 40, 246-250.

Phillips, N. F. B., Li, Z. \& Lindmark, D. G. (1997). Isolation of a pyrophosphate-dependent phosphofructokinase from Hexamita inflata. Mol Biochem Parasitol 90, 377-380.

Schofield, P. J., Costello, M., Edwards, M. R. \& O'Sullivan, W. J. (1990). The arginine dihydrolase pathway is present in Giardia intestinalis. Int J Parasitol 20, 697-699.

Thompson, R. C. A., Reynoldson, J. A. \& Mendis, A. H. W. (1993). Giardia and giardiasis. Adv Parasitol 32, 71-160.

Townson, S. M., Hanson, G. R., Upcroft, J. A. \& Upcroft, P. (1996). Characterisation and purification of pyruvate: ferredoxin oxidoreductase from Giardia duodenalis. Mol Biochem Parasitol 79, 183-193.

Wilhelm, E. R., Battino, R. \& Wilcock, R. J. (1977). Low pressure solubility of gases in liquid water. Chem Rev 77, 219-262.

Received 30 March 2001; revised 1 June 2001; accepted 11 July 2001 